\title{
Telegram App in Learning English: EFL Students' Perceptions
}

\author{
Zahra A. Abu-Ayfah ${ }^{1}$ \\ ${ }^{1}$ College of Education, Taibah University, Medina, Saudi Arabia \\ Correspondence: Zahra A. Abu-Ayfah, College of Education, Taibah University, Medina, Saudi Arabia.
}

Received: November 3, 2019

Accepted: December 9, 2019 Online Published: December 11, 2019

doi: 10.5539/elt.v13n1p51

URL: https://doi.org/10.5539/elt.v13n1p51

\begin{abstract}
The rapid growth of mobile device technology and the emergence of new mobile device applications such as Telegram have created new opportunities for EFL students. Accordingly, the current study investigated the EFL College students' perceptions of using Telegram for English language learning. The participants of the present study were 300 EFL college students, 200 female and 100 male were selected randomly from the department of English and Translation at Tibah University in AL-Medina AL-Manwarah in Saudi Arabia. This study followed a quantitative approach in which a survey questionnaire was utilized as an instrument for data collection. The results revealed that the majority of EFL students perceived Telegram as a useful tool for English language learning, particularly in vocabulary learning. The findings of the present study may contribute to developing the process of improving learning techniques in higher education in Saudi Arabia.
\end{abstract}

Keywords: telegram app, EFL, perceptions, college students

\section{Introduction}

In an internationalized 21st Century, efficiency in other languages conduces to efficient collaboration and communication with people from varied cultural backgrounds in all fields of life, education, and work. Reasonably, therefore, language learning must be a crucial lifelong continuation, accomplished in a diversity of ways according to social, working, and educational life necessities, as well as personal needs and interests (Kukulska-Hulme, Agnes; Lee, Helen and Norris, 2017). One of the most imperative languages these days is the English language. It is the most spoken language in the word (Cholakova, 2015; krajnakova, 2012; Rohmah, 2005). It is the language of different science such as computers, aviation, tourism, and diplomacy. Therefore, much effort is exerted to find appropriate methods in learning English. English language learning (ELL) is a very complicated process. It needs a cooperative, mighty and extraordinary effort extended from both learners and educational institute (Kanno \& Stuart, 2011; Khasbani, 2018; Wright, 2010).

The current generation of EFL students is growing up in a digital world. Using mobile devices is an enormous part of their daily experience outside educational situations (Chen, 2017; Ivić \& Jakopec, 2017). A huge part of social communications is occurring online; since the language of the internet has a substantial effect on the users' language, it should be crucial to do a study on such issues and investigate their role in ELL (Ghobadi \& Taki, 2018).

In the mobile world, the use of mobile devices has been integrated rapidly into EFL teaching and learning in all their aspects (Ozer \& Kiliç, 2018; Zou et al., 2018). Both instructors and students use mobile devices to achieve verity of educational purposes. Moreover, a countless number of English learning apps encourage students to practice different language skills without limitations of time, place, or cost (Ahn, 2018; Eppard, Nasser, \& Reddy, 2016). The global tendency towards mobile device learning apps urges the researchers to the necessity of examining the implementation of mobile apps in English language learning.

One of the mobile apps is 'Telegram.' It is a cloud-based app which allows users to exchange videos, pictures, audio, or any file stored in a server without occupying space in their mobile device (Abbasi \& Behjat, 2016; Ghobadi \& Taki, 2018; Serostanova, 2014).There is a sharp trend towards using Telegram, with 200 million users monthly in 2018 as the Telegram Company claimed (www.telegram.org).

Telegram app has different contributions among different fields other than education field. It is a suitable platform for advertisement through which many advertising and business associations promote their services and products, make awareness and receive feedback from consumers (Yinka \& Queendarline, 2018). Different 
studies express the argument of whether the telegram app develops or reduces teaching and learning English language process.

Many previous studies proved the effectiveness of the Telegram app in teaching and learning the English language (Heidari-shahreza \& Khodarahmi, 2018; Xodabande, 2017). The adoption of Telegram in English language learning ameliorate different angles of EFL learners' English language skills, such as reading comprehension ability (Naderi \& Akrami, 2018), vocabulary (Ghobadi \& Taki, 2018), writing skill (Aghajani \& Adloo, 2018), and improving speaking skill (Setiawan \& Wahyuni, 2017; Xodabande, 2017). However, it is crucial to know how EFL students find Telegram as a tool that assists them in English language learning.

It is essential to cognize that students' perception of telegram plays a critical role in defining the success of the Telegram app. If English students perceive that Telegram is easy to apply and useful, they tend to show a high of both satisfaction and motivation, and positive attitude, which will lead them to deduce this app (Ahn, 2018).

Furthermore, Gangaiamaran and Pasupathi (2017) recommended for future study that there is a need to shed light on students' perceptions towards mobile apps as an ELL tool; nevertheless, Dashtestani (2013) pointed to the necessity of conducting more research to evaluate the efficiency of the implementation of MALL from the overview of language learners.

Regarding the researcher's experience and research's limitation, the Saudi context does not have any published studies that discussed the perception of EFL college students of using the Telegram for English language learning.

Thus, the study investigated the EFL college students' perception of using Telegram for English language learning.

The findings of the current study may contribute to developing the process of improving learning techniques in higher education in Saudi Arabia. It may draw college students' attention to the importance of EFL mobile applications and their role in providing different EFL activities, as well as it may raise students' awareness toward implementing mobile apps in EFL learning process, and in improving EFL learning process. Also, it might encourage self-study and change in the learners' roles.

It may give an indication to the decision makers and Saudi educationalists positively or negatively about the benefit of the EFL mobile apps to students, which helps them to improve the educational process for EFL. In other words, it may afford insight to administrators of university and scholars to enhance the process of teaching and learning a foreign language in Saudi Arabia. Moreover, it may encourage apps providers to modify, improve or create a verity of EFL educational applications.

\section{Literature Review}

Many previous studies proved the effectiveness of the Telegram app in teaching and learning the English language (Heidari-shahreza \& Khodarahmi, 2018; Xodabande, 2017). The adoption of Telegram in English language learning ameliorate different angles of EFL learners' English language skills, such as reading comprehension ability (Naderi \& Akrami, 2018), vocabulary (Ghobadi \& Taki, 2018), writing skill (Aghajani \& Adloo, 2018), and improving speaking skill (Setiawan \& Wahyuni, 2017; Xodabande, 2017).

Akobirov and Vokhidova (2018) discussed the significance of mobile learning in teaching and learning the English language. They focused on mobile application "Telegram." Their study showed that using Telegram in teaching language skills could be very promising and useful.

Telegram app has an impact on English language skills such as reading, writing, listening, and speaking. Naderi and Akrami (2018) stated that using telegram groups in instruction has a significant effect on the learners' reading comprehension ability. They affirmed that it improved the learners' ability in reading comprehension.

In the same context of implementing Telegram app in the educational process of English skills, there were two of a previous study (Abbasi \& Behjat, 2016; Setiawan \& Wahyuni, 2017; Xodabande, 2017) which concentrated on improving speaking ability. Abbasi and Behjat (2016) investigated the effect of storytelling with Telegram on EFL students 'speaking complexity. The result showed that the experimental group outperformed the control group regarding their speaking complexity.

Additionally, Setiawan and Wahyuni (2017) showed the role of E-talk Castel's model in improving students' speaking skill in English by using a recording tool in telegram application. The results revealed that implementing E- talk castle model supported by Telegram provided students with good aid to improve their English speaking skill. 
Setiawan and Wahyuni's (2017) study is affirmed by Xodabande (2017) who examined the usability of Telegram in teaching pronunciation of the English language to EFL learners. The findings showed that the use of Telegram contributed significantly to amelioration in participants' pronunciation. The researcher indicated that teaching the English language using Telegram can be promising and very useful.

Another English skill that was taught with implementing the Telegram app was writing ability. Aghajani and Adloo (2018) stated that participants in Telegram Cooperative writing groups displayed slightly higher scores compared to face-to-face cooperative writing groups. They claimed that popular mobile devices bring a vast potential to Telegram learning regarding pervasiveness, ubiquity, personalization, and flexibility.

The Telegram also has contributions in vocabulary acquisition of the English language. One of the telegram features is stickers which have a crucial role in vocabulary acquisition. Ghobadi and Taki (2018) indicated that teaching vocabulary via Telegram stickers could assist in outstanding advantages for the learners. The researchers stated that Telegram had a positive impact on learning new vocabulary items among EFL learners.

The results of Ghobadi and Taki (2018) came in line with the findings of a case study done by Heidari-shahreza and Khodarahmi (2018). The authors explored the Telegram role in mastering word stress patterns of English language by EFL learners. The findings showed a statistically significant difference in the fever of the experimental group.

Moreover, the students had a positive attitude about learning new words via Telegram. Ghaemi and Golshan (2018) examined the effects of short messages services (SMS) via Telegram on EFL students' vocabulary learning process. The researchers assert that the use of SMS via Telegram as a teaching tool affected students' vocabulary learning positively.

On the other hand, Bello and Hadiza (2017) indicated the usability of using Telegram as a teaching tool. They assigned that Telegram could provide English teachers with appropriate materials to produce valuable and fabulous instructions. The researchers recommended English teacher to prepare well to be able to use Telegram in the classroom efficiently.

Nevertheless, Zarei (2015) examined the effectiveness of using Telegram app as teaching tools for language learning. The study used mixed to investigate the effect of using Telegram app on providing feedback and developing writing accuracy in L2 and to investigate students' perceptions of using Telegram app for writing purpose. The findings showed that the experimental group using Telegram have better performance than the control group. Student perceptions showed usefulness and satisfaction of using Telegram app for writing purpose.

Ibrahim, Norsaal, Abdullah, Soh, and Othman (2016) and Yinka and Queendarline (2018) concentrated on students' perception toward implementing Telegram in English teaching and writing. Yinka and Queendarline (2018) found out that students use telegram for both learning and teaching purposes. They recommended that the telegram using have to be combined into the curriculum of the higher institution to develop the education of Universities.

Furthermore, Ibrahim et al. (2016) indicated that the Telegram app supports learning and teaching enhancement by offering a quick and easy way of creating and sharing information.

Many of previous studies were conducted on the effectiveness of the Telegram app in teaching and learning English language skills (Aghajani \& Adloo, 2018; Heidari-shahreza \& Khodarahmi, 2018; Xodabande, 2017). However, there are little previous studies that examine the learners' perception of using Telegram as a mobile device' application in EFL education (Zamakhsari, 2018).

Besides, in the Saudi context, smartphone proved its outperformance in EFL learning. Ahmed (2015) examined smartphones enhancement of EFL learning mainly on linguistic knowledge and language skills. The research sheds light on learners' vocabulary acquisition, listening, speaking, reading and writing. The researcher affirmed that EFL students who used smartphones were more enthusiastic than those who were still held in paper-text materials. This affirmation was reinforced by Al Fadda \& Al Qasim (2013) who shed light on improving listening comprehension via podcasting. The authors exposed that applied of podcasts can create a positive and significant difference to the EFL listening comprehension for EFL Saudi students.

Nevertheless, Hazaea \& Alzubi (2016) showed that applying WhatsApp, mobile camera, online and offline dictionaries, memos and online resources improved the students' text participation practices and code-breaking practices while text-analyzing practices and text using were faintly improved. Taking into account the studies conducted in the Saudi context; the MALL proved its effectiveness among EFL students in Saudi Arabia. 
However, according to search and limitation of the researcher, no any published study in the Saudi context discusses the perception of EFL Learners towards using the Telegram as a mobile device' application to enhance learning the English language.

Despite that any decision relating to integrating new technology into the educational process is often made by the decision maker, the success of this integration is based on the students' intentions to accept and adopt this new technology. Thus, knowing how individuals perceive new technology has been of interest to many researchers. Furthermore, it is crucial to understand the reasons why some students accept and adopt a particular technology and reject another (Al-Lozi, Al-Hujran, \& Al-Debei, 2016).

Therefore, the current study aimed to investigate EFL college students' perception of using Telegram in English language learning. The results reflection of the current study may provide an understanding of mobile learning, particularly ELL via Telegram. It would assist decision makers in developing successful strategies for M-Learning adoption. Shortly, this research sought to answer the following question: What are the EFL college students' perceptions of using Telegram app for English language learning?

\section{Method}

\subsection{Research Approach}

This descriptive study makes use of a quantitative research strategy in the sense that there will be quantitative data was produced.

\subsection{Population and Sample}

The number of population was (1609) including (1161) female and (448) male. The percentage of the sample was (23\%). They were 300 EFL college students, 200 female and 100 male selected randomly, based on simple random sampling, from the department of English and Translation at Tibah University in AL-Medina AL-Manwarah in Saudi Arabia.

\subsection{The Participants' Demographics}

Three hundred of EFL college students participated in the study. Descriptive statistics for the participants' demographic information are listed in the Figure1.

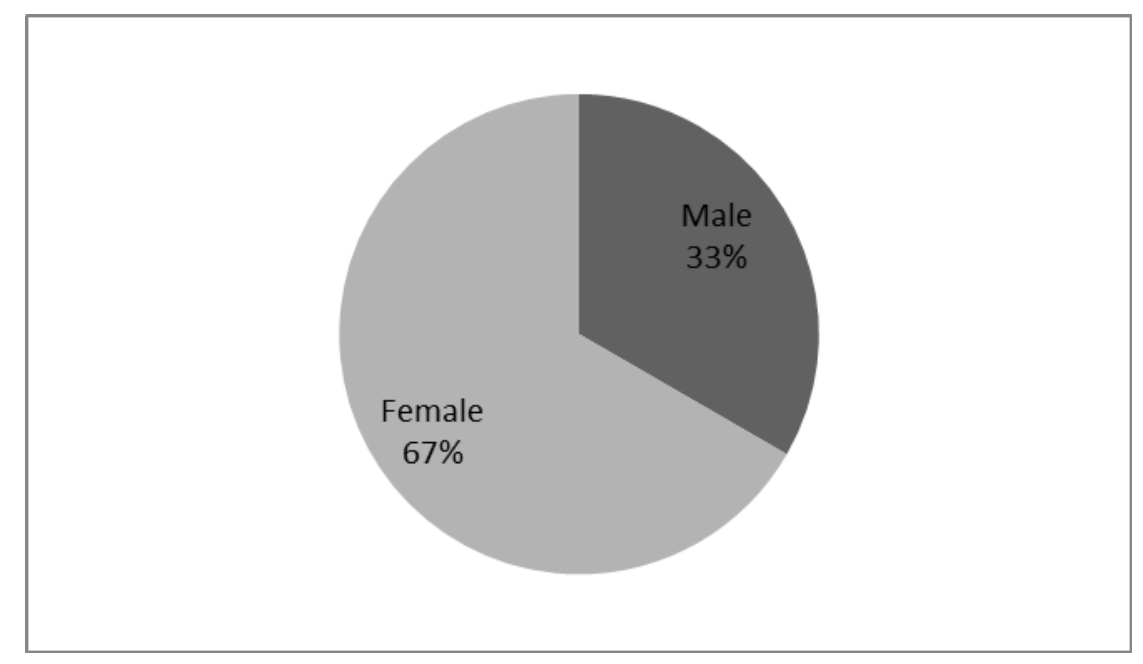

Figure 1. Description of the sample gender

Males comprised 100 (33\%) of the participants, while females predominated, with 200 (67\%). 


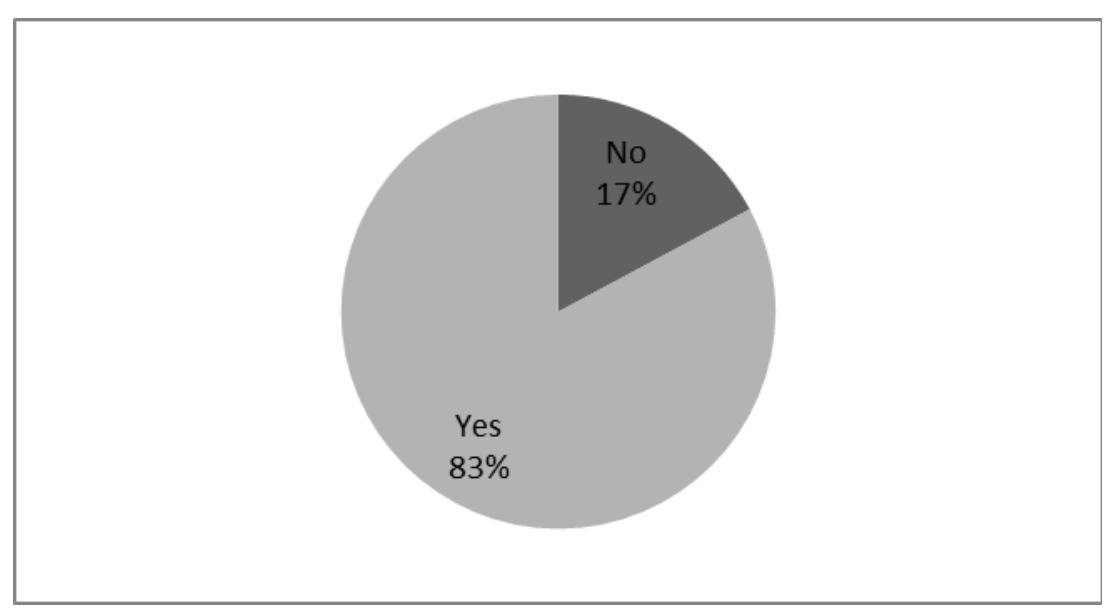

Figure 2. Do you use Telegram

Regarding the user of Telegram App, there are about (83\%) of students use Telegram, while about $17 \%$ of students don't use it as illustrated in the Figure 2.

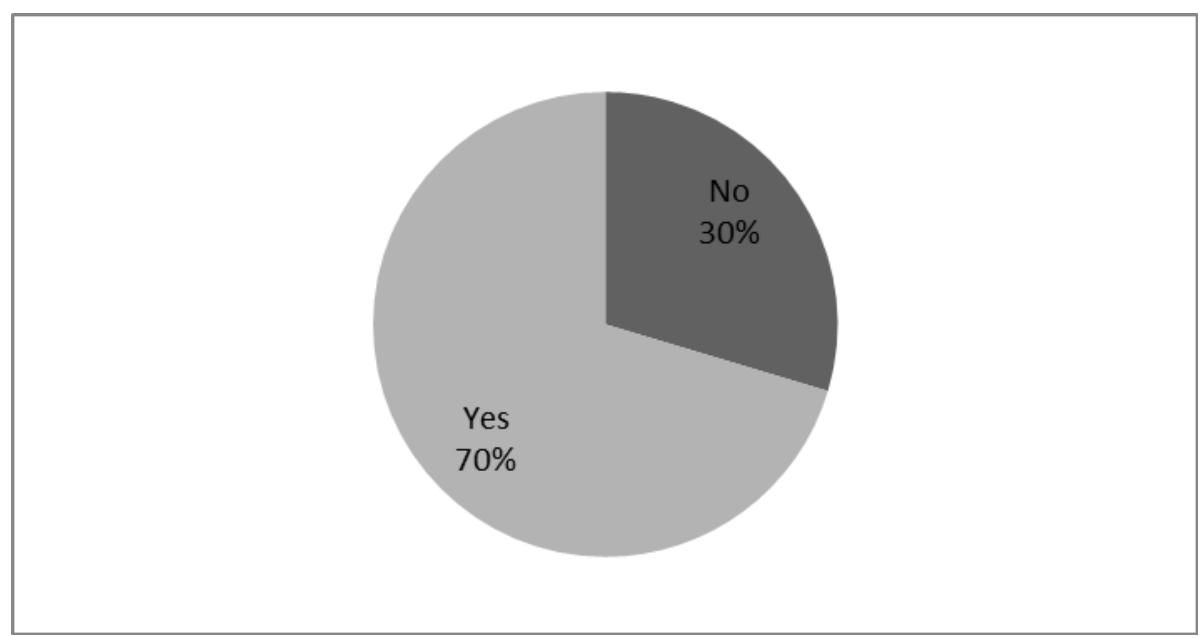

Figure 3. Do you intend to use Telegram

Among the Telegram nonusers, 38 (70\%) intended to use it in the future as appeared in the Figure 3.

\subsection{Data Collection Procedures}

To achieve the study goal, the researcher collected data via a questionnaire. The statements of the questionnaire were self-built with slight reliance on previous studies (Abdu \& Ramani, 2011; Ahn, 2018; Heidari-shahreza \& Khodarahmi, 2018; Ibrahim et al., 2016; Martin, 2013; Yinka \& Queendarline, 2018) and modified to correspond the research purposes. Secondly, the instrument was evaluated by professionals to assess its content validity. About five professionals from the Department of Teaching English for Other Speakers of Language (TESOL) reviewed the questionnaire and provided the researcher with their feedbacks. The questionnaire was then modified and revised based on the professionals' feedback. After that, the questionnaire was submitted to the Deanship for Graduate Studies to attain accreditation and to extract a letter facilitating the task of the researcher. Lastly, the final version was in its ultimate form.

The participants had to complete an individual questionnaire. All of the participants approached online, and the questionnaire was presented via Google online survey. The researcher distributed the questionnaire among 300 EFL college students via Whatsapp group. It took place on March 6, 2019. The full transcripts of the questionnaire will be attached in the appendix" 1 ".

The students were not required to identify themselves in the questionnaire. Both demographic information and questionnaire results were completely confidential and used for the current study only. No specific information related to students' identity was solicited or obtained. 


\subsection{Instrument Design}

A questionnaire was selected for this study because it is a reliable and quick method to collect data from multiple respondents in an effective and timely manner. It is especially dynamic when it comes to large projects, where time is one of the significant constraints (Bell, 2005). The questionnaire will be a quick and effective way for the researcher to reach multiple respondents within several weeks.

For the current research, the researcher designed questionnaire scripts. The questionnaire consists of two sections. The first section of the instrument consists of demographic questions, related to the participants' gender and the participants' actual use of Telegram App. The second section includes twenty-four statements related to the research issue. It was self-built based on some of previous studies (Abdu \& Ramani, 2011; Ahn, 2018; Heidari-shahreza \& Khodarahmi, 2018; Ibrahim et al., 2016; Martin, 2013; Yinka \& Queendarline, 2018). The researcher divided the core statements into six dimensions, each dimension addressing one of four English Skills or the other English aspects such as grammar or vocabulary. The current study used a 5-point Likert scale which one denotes "strongly disagree" and the response of fife means "strongly agree."

\subsection{Validity and Reliability of the Questionnaire}

The questionnaire was created as an online questionnaire via the Google survey to facilitate and accelerate data collection and to reach all the participants whether they are male or female.

For reliability, the researcher used a pilot study and distributed the questionnaire via the Google survey among EFL college students at Tibah University. The researcher received 50 responses. Then, the researcher applied the reliability test; the instrument produced a highly reliable result as it appeared in table 1 which is a Cronbach Alpha of 0.907.

Table 1. Cronbach Alpha Coefficients

\begin{tabular}{ll}
\hline Reliability Statistics & \\
\hline Cronbach's Alpha & N of Items \\
.907 & 24
\end{tabular}

For validity, the jury members examined the validity of the instrument and provided the researcher with some modifications.

\subsection{Methods of Data Analysis}

The current study will apply the descriptive, analytical method because of the large number of respondents, and because of the quantitative research approach of the study. The researcher will use the statistical software available SPSS.

Descriptive statistics were calculated to investigate the students' perceptions of using Telegram app for ELL. The data were collected via Google online survey. Then, the data were saved as an Excel file. Lastly, it was converted to SPSS data. They were presented using frequency and percentage of the participants' response to all survey statements.

\section{Findings}

As illustrated in the Figure 4, the large majority of participants 264(82\%) who use Telegram, and (33\%) use it 3-4 times/ a week. 


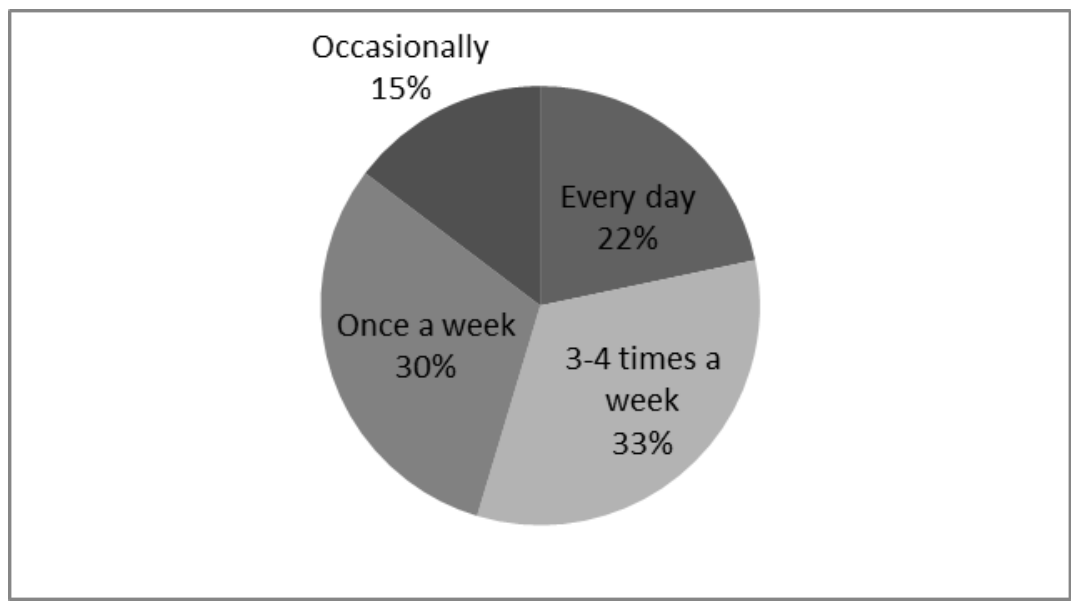

Figure 4. How often do you use Telegram

Followed by $(30.7 \%)$ students use Telegram once a week, while $(21.7 \%)$ of students use it every day. Only a small number of students (14.7\%) use it occasionally.

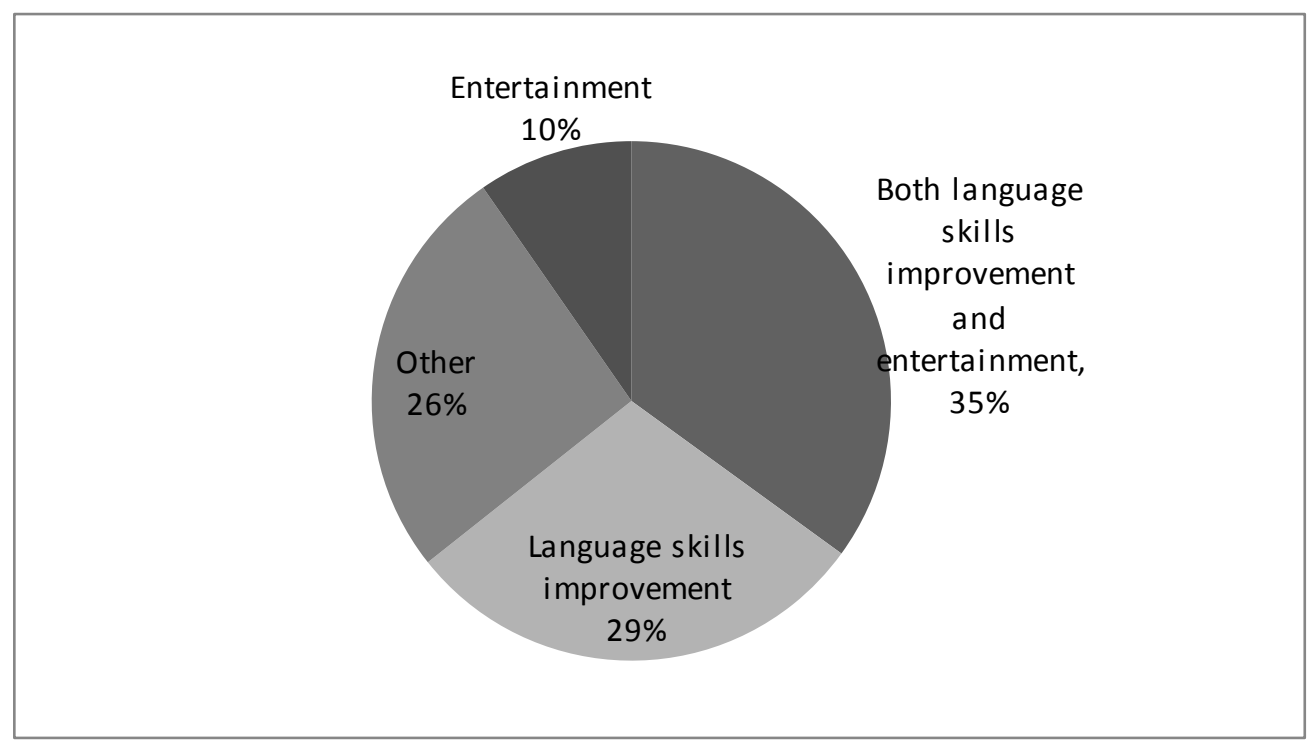

Figure 5. Description of the reason that participants use Telegram

Regarding the reason that participants use Telegram for, the majority of participants (35\%) use telegram for both language skills improvement and entertainment as illustrated in the figure " 6 ", while (29\%) of participants use it for language skills improvement. About (26\%) of participants use it for other purposes and the last portion (10\%) of participants use it for entertainment.

\subsection{General Usage of Telegram App for English Language Learning}

The descriptive statistics for usage of Telegram for listening skill, speaking skill, reading skill, writing skill, grammar, and vocabulary are listed in the Table 2 .

Table 2. Descriptive statistics related to dimension

\begin{tabular}{ccccc}
\hline & Mean & Std. Deviation & $\%$ & Rank \\
listening & 14.30 & 3.03105 & 57.6 & 4 \\
speaking & 14.27 & 3.06127 & 56.8 & 5 \\
Reading & 14.80 & 2.98009 & 64 & 2 \\
writing & 14.25 & 3.18559 & 56.7 & 6 \\
Grammar & 14.67 & 2.97255 & 62.9 & 3 \\
Vocabulary & 15.06 & 3.09759 & 66 & 1 \\
\hline
\end{tabular}


The highest English language skill that students use Telegram app for, is vocabulary learning (66\%) as identified by participants. This dimension is ranked as (1) out of (6) dimensions in the questionnaire. Its mean is (15). As appeared in table (2), the vocabulary learning was followed by the reading skill that $192(64 \%)$ of students found Telegram appropriate for reading skill, it is ranked as (2) and its mean (14.8). For grammar learning (62.9\%), which came in the third rank and the mean is (14.7). For listening skill, the mean is (14.3) and it is ranked as (4). For speaking skill (56.8\%), the mean is (14.28) and it is ranked as (5) from six dimension. The smallest portion of students $170(56.7 \%)$ perceived that Telegram is suitable for writing skill. Its mean is (14.25).

\section{Discussion}

The study question is: What are the EFL college students' perceptions of using Telegram app for English language learning?

The survey included several questions about the general usage patterns for the Telegram app, and specific use for English language learning.

For general usage patterns for the Telegram app, the majority of EFL college students (82\%) who use Telegram, among them (33\%) students use Telegram 3-4 times/ a week, and (31\%) use it once a week. Followed by (22\%) use it every day, while only (15\%) students, use it occasionally. While among $17 \%$ of students who do not use Telegram, $38(70 \%)$ intended to use it in the future. This demonstrates that Telegram has become a primary app of mobile device applications among EFL college students. This implies that there is not only a rapid increase in the number of Telegram users but also an increasing possibility of using Telegram in English language learning. According to (https://telegram.org/faq), Telegram users were rapidly increased with 200 million users monthly in 2018.

This study also examined the reasons for students' general usage of Telegram. Almost of EFL college students (35\%) use Telegram for ELL and entertainment; however (29\%) students use it for ELL only. The results indicated that $(65 \%)$ of students use Telegram for ELL. From this result, it can be appeared that many students apparently trust Telegram and based on it for ELL purposes, which is in line with the findings of Ibrahim et al. (2016) who found that the Telegram is an easy learning tool for sharing information and teaching and learning process. They also indicated that the Telegram is a useful tool that supports students' language learning process. The result of the current study is also in agreement with Yinka and Queendarline (2018) who found that students use telegram for teaching and learning purposes, and they asserted that Telegram is a useful extension of the classical learning methods.

This phenomenon can be attributed to many Telegram features such as security, free open source platform, and a cloud-based messenger, and mean of which both textual and non-textual messages can be exchanged among users as well as voice calls (Ahn, 2018; Wang \& Smith, 2013; Yinka \& Queendarline, 2018). In this process, the Telegram app has become a necessity and a trusted companion of students.

According to the actual use of Telegram based on the verity of English language skills, most of the students (66\%) preferred to use Telegram for vocabulary learning, and the majority of them identified that using Telegram in learning vocabulary supply them with new vocabularies which are commonly used in daily life. This result indicates that students prefer to use mobile devices apps to improve receptive skills such as vocabulary than other language skills. This is consistent with a previous study of Ahn (2018) who stated that mobile device apps are widely used by students to develop their receptive skills than productive skills.

This result is also consistent with previous studies by Ghaemi and Golshan (2018) and Ghobadi and Taki (2018). It may imply that Telegram had a strong positive effect on the vocabulary learning of EFL students. Ghaemi and Golshan (2018) asserted that the application of mobile learning and mainly the Telegram based learning environments are a possible solution for the vocabulary learning problem. Also, Ghobadi and Taki (2018) affirmed that vocabulary learning could be facilitated via presenting the words through the Telegram app. They claimed that based on the efficiency of Telegram as a technological tool, learning new words can also be facilitated as learners can directly associate the meanings of the new words with the interesting stickers on Telegram app. Further, the result of the present study could be demonstrated by a study of Heidari-shahreza and Khodarahmi (2018) which affirmed that the speed and suitability of utilizing Telegram made obvious that receiving instruction as the acquisition of word stress pattern via Telegram outperformed receiving traditional learning.

The results of a present study also show that vocabulary learning was followed by the reading skill that 192 (64\%) of students found Telegram appropriate for reading ability. It implies that Telegram is an effective platform for reading learning. It also proves that Students could favor Telegram as they enjoy the comfort of 
using it. The results of the current study were in line with the findings of Naderi and Akrami (2018) who concluded that using the new technologies of mobile phone such as Telegram app is helpful for teaching reading comprehension. Nevertheless, the study of Shirinbakhsh and Saeidi (2018) proved that the practice of reading comprehension was facilitated for EFL students through Telegram.

From the results illustrated in the table (3) the highest mean score (3.62) was obtained for item st13, "Using Telegram makes the learning of reading skill more fun." This finding proved by Laghari et al. (2017) who concluded that students were happy, excited, and motivated to learn via M-learning application.

For grammar learning, (62.9\%) of students confessed the usability of Telegram in grammar learning, among them $(67 \%)$ of students indicated the Telegram role in enhancing their ability to use grammar correctly in EFL. This implies that Telegram has an accepted effect in improving grammar learning among students. The results echo the results of the study conducted by Mahmoud and Laban (2017), who concluded that mobile learning application is more efficient and has supremacy over the traditional method in teaching and learning the English language in general and grammar learning in particular. Also, the result is consistent with the previous studies by Wang and Smith (2013) who affirmed that students perceived mobile device assisted learning positively as an effective method for developing reading and grammar ability. Furthermore, the finding is also compatible with the results of Baleghizadeh and Oladrostam (2010) which showed the effectiveness of using mobile phones in increasing the grammatical ability of students.

Regarding the result of listening skill, almost 172 (57.6\%) of students found Telegram suitable for listening skill; even it is ranked less than vocabulary, grammar and reading skills. The result is in contrast with the results of Gangaiamaran and Pasupathi (2017) which showed that listening skill was enhanced successfully by mobile applications than other English language skills. However, the current study's result revealed that students still perceived the Telegram as an appropriate tool for listening learning. It implies that students might be found Telegram easy to use anywhere and anytime as well as it provides them with real context to practice the listening skill. The finding of the present study is in agreements with the results of the study by Kim (2013) which asserted that the authentic context and immediacy play a crucial role in developing listening skills; it also illustrated that if students are provided with good mobile apps as a learning resource, they would be more motivated and proficient listeners.

The result is also reinforced by Al Fadda and Al Qasim (2013) who affirmed that applying mobile device application particularly podcasting can create a positive and significant difference to the EFL listening comprehension for EFL Saudi students.

According to speaking skill, almost 170 (56.8\%) perceived that using Telegram makes speaking English easier. It indicates that students regarded Telegram as a suitable tool for speaking skill learning. The result of the currents study is consistent with the findings of a previous study of Setiawan and Wahyuni (2017) who stated that E-talk castle model via Telegram app gives good contribution for the students to improve their speaking skill in the English language. It is also in line with the result of the study of Abbasi and Behjat (2016) which assigned that the storytelling through Telegram app could improve learners' speaking complexity. The findings seemed to be compatible with the views of Xodabande (2017) who indicated that the use of Telegram contributed significantly to the improvement in students' pronunciation EFL. The finding is also compatible with the results of Baleghizadeh and Oladrostam (2010) who affirmed that giving the responsibility of learning to students and emphasizing the social nature of learning were behind the success of mobile learning applications in improving grammatical accuracy while speaking.

It is evident that there is a slight difference between the results of speaking skill and listening skill as well as between them and writing skill. It implies that students perceived the Telegram app as a useful tool for ELL in general. This finding demonstrates Akobirov and Vokhidova (2018) believe that the Telegram app will remain to serve EFL students on their way to master the English language.

The smallest portion of students (56.7\%) perceived that Telegram is useful for English writing learning. Being ranked as a last one of English language skill does not mean that Telegram has no role as a tool in writing learning, however that could be illustrated by study of Aghajani and Adloo (2018) which indicated that Telegram app is a tool that significantly assists students improving their writing and develops the word choice in their writing task. This is also supported by Zarei (2015) study which proved the efficiency of integrating Telegram into L2 classes especially for writing tasks which are considered boring on the part of learners. 


\section{Conclusion}

The present study investigated EFL college students' perception of using Telegram in ELL. In other words, students' perception of using Telegram in ELL, including listening skill, speaking skill, reading skill, writing skill, grammar learning, and vocabulary learning, were examined.

It confirmed that the Telegram today is almost an integral part of EFL college students' daily lives. The current study's findings indicated that the majority of EFL college students prefer to use telegram for language skill improvement. Furthermore, the results revealed that the most of students favored to learn vocabulary via Telegram than other language skills; which could be attributed to the view of Ahn (2018) that mobile device apps are widely used by students to develop their receptive skills than productive skills.

Once again, the efficiency of the technology was evidenced, and Telegram is perceived as a venue for ELL, which could be attributable to a number of its features such as its ubiquity, ease of access, ease of sharing personal ideas and peer feedback as well as the teacher's feedback to individual students. Furthermore, students can enjoy the comfort of using it which could be catered to their own needs and to a capability of Telegram to provide them with a feeling of security.

In light of the findings, Telegram app could be incorporated into higher education curriculum to improve Universities educational process. This study suggests that instructors can use Telegram app as a complementary tool for face to face instruction and assessment. Furthermore, EFL students can use Telegram app to improve their English language outside the classroom. However, EFL students need to be educated to exploit the Telegram app in improving other English language skills than vocabulary learning. It is also recommended to use Telegram app to encourage self-study and to change the learners' role.

The result may assist in improving mobile learning in high education, as well as encourage self-study. Despite the rapid increase in MALL research, studies on Telegram in Saudi college setting based on students' perception are still limited. Thus, this study may provide a foundation for similar research in the future.

Moreover, it may give an indication to the decision makers and Saudi educationalists positively or negatively about the benefit of the EFL mobile apps to students, which helps them to improve the educational process for EFL.

In what follows, some issues need to be more investigated on the use of Telegram were briefly suggested. This study only examined using Telegram in English language learning on the part of students. Thus, future research may explore teachers' perception of Telegram and their use or willingness to use it as part of their instruction. Furthermore, it is recommended to investigate the barriers to using Telegram app in ELL.

\section{Acknowledgement}

First and Foremost praise is to ALLAH, the Almighty, the greatest of all, on whom ultimately we depend for sustenance and guidance. I would like to thank Almighty Allah for giving me opportunity, determination and strength to do my research. His continuous grace and mercy was with me throughout my life and every more during the tenure of my research.

I have taken efforts in this project. However, it would not have been possible without the kind support and help of many individuals. I want to extend my sincere thanks to all of them.

I want to express my gratitude to my supervisor Prof. Antar Abdellah for his guidance and constant supervision as well as for providing necessary information regarding the project $\&$ also for his support in completing the project.

I would like also to express my deepest gratitude and thanks to Dr. Hayat Alamri for her helpful suggestions about questionnaire, for her useful comments, remarks, and her invaluable support and guidance.

Special gratitude and thanks go to Dr. Maha Khasem for her quick response and her valuable comments and feedback.

My thanks and appreciations also go to people who have willingly helped me out with their abilities.

Thanks for all your encouragement.

\section{References}

Abbasi, M., \& Behjat, F. (2016). The effect of storytelling on Iranian EFL learners' speaking complexity. Studies in English Language Teaching, 4(4), 416. https://doi.org/10.22158/selt.v4n4p416

Abdu, M. A.-M., \& Ramani, P. N. (2011). Difficulties in teaching and learning grammmar in an EFL context. International Journal of Instruction, 4(2), 69-92. 
Aghajani, M., \& Adloo, M. (2018). The effect of online cooperative learning on students' writing skills and attitudes through Telegram application. International Journal of Instruction, 11(3), 433-448. https://doi.org/10.12973/iji.2018.11330a

Ahmed, M. D. (2015). Can smartphones pave the path towards EFL competence for Saudi college students? Education and Linguistics Research, 1(2), 120. https://doi.org/10.5296/elr.v1i2.8467

Ahn, S. K. (2018). Korean EFL college students 'acceptance and use of smartphone applications for English language learning. ProQuest.

Akobirov, F., \& Vokhidova, N. (2018). A new generation of English learners-Telegram app users.

Al-Lozi, E., Al-Hujran, O., \& Al-Debei, M. M. (2016). Get ready to mobile learning: examining factors affecting college students' behavioral intentions to use m-learning in Saudi Arabia. Jordan Journal of Business Administration, 10(1), 111-128. https://doi.org/10.12816/0026186

Al Fadda, H., \& Al Qasim, N. (2013). From call to mall: the effectiveness of podcast on EFL higher education students' listening comprehension. English Language Teaching, 6(9), 30-41. https://doi.org/10.5539/elt.v6n9p30

Baleghizadeh, \& Oladrostam. (2010). The effect of mobile assisted language learning ( MALL ) on grammatical accuracy of EFL students. MEXTESOL Journal, 34(2), 1-10.

Bello, M. L., \& Hadiza, B. D. (2017). Revitalizing education through: integrating telegram as corrective feedback in language teaching muhammad ladan bello and bello dange hadiza. SER, 17(2), 99-104. https://doi.org/10.35386/ser.v17i1.21

Gangaiamaran, R., \& Pasupathi, M. (2017). Review on use of mobile apps for language learning. International Journal of Applied Engineering Research, 12(21), 11242-11251.

Ghaemi, F., \& Golshan, N. S. (2018). The impact of Telegram as a social network on teaching English vocabulary among Iranian intermediate EFL learners. International Journal of Information and Communication Sciences, 2(5), 86. https://doi.org/10.11648/j.ijics.20170205.15

Ghobadi, S., \& Taki, S. (2018). Effects of Telegram stickers on English vocabulary learning: focus on Iranian EFL learners. Research in English Language Pedagogy, 6(1), 139-158.

Hazaea, A. N., \& Alzubi, A. A. (2016). The Effectiveness of using mobile on EFL learners' reading practices in Najran university. English Language Teaching, 9(5), 8. https://doi.org/10.5539/elt.v9n5p8

Heidari-shahreza, M. A., \& Khodarahmi, Z. (2018). Effect of MALL on the acquisition of word stress patterns of English by Iranian EFL learners: the case of Telegram. Journal of Applied Linguistics and Language Research, 5(1), 40-55. Retrieved from https://www.researchgate.net/publication/322488415\%0AEffect

Ibrahim, M. N. Bin, Norsaal, E. B., Abdullah, M. H. Bin, Soh, Z. H. B. C., \& Othman5, A. Bin. (2016). Preliminary perception of teaching and learning using Telegram social media tool. Jurnal Intelek, 12(2), 95-103.

Kim, H.-S. (2013). Emeriging mobile apps to improve English listening skills. Multimedia-Assisted Language Learning, 16(2), 11-30. https://doi.org/10.15702/MALL.2013.16.2.11

Laghari, Z., Kazi, H., \& Nizamani, M. (2017). Mobile learning application development for improvement of English listening comprehension. International Journal of Advanced Computer Science and Applications, 8(8), 229-237. https://doi.org/10.14569/IJACSA.2017.080830

Mahmoud, M., \& Laban, A. (2017). The effectiveness of using mobile learning in developing eleventh graders , English grammar learning and motivation for English. The Islamic University-Gaza Research. Retrieved from http://hdl.handle.net/20.500.12358/18819

Martin, K. (2013). Making use of ICT for teaching and learning English at lower and upper secondary schools. Charles University Iin Prague, 1-40.

Naderi, S., \& Akrami, A. (2018). EFL learners' reading comprehension development through MALL: Telegram groups in focus. International Journal of Instruction, 11(2), 339-350. https://doi.org/10.12973/iji.2018.11223a

Setiawan, R., \& Wahyuni, N. C. (2017). English talk class based Telegram (E-talk castel) an innovative and creative strategy to stimulate students' speaking skill. English Language and Literature International Conference, 1, 195-199. https://doi.org/10.29408/veles.v1i1.389 
Shirinbakhsh, S., \& Saeidi, F. (2018). The effectiveness of Telegram for improving students' reading ability. Journal of Applied Linguistics and Language Research Volume, 5(4), 118-129.

Wang, \& Smith. (2013). Reading and grammar learning through mobile phones. Language Learning \& Technology, 17(3), 117-134.

Xodabande, I. (2017). The effectiveness of social media network telegram in teaching English language pronunciation to Iranian EFL learners. Cogent Education, 4(1), 1-14. https://doi.org/10.1080/2331186X.2017.1347081

Yinka, A. R., \& Queendarline, N. N. (2018). Telegram as a social media tool for teaching and learning in tertiary institutions. International Journal of Multidisciplinary Research and Development, 5(7), 95-98.

Zamakhsari, Z. (2018). Online learning: students participation and satisfaction. International Journal on E-Learning and Higher Eduction, 6(January 2017).

Zarei, N. (2015). A tellecollaborative approach to written corrective feedback. International Conference ICT for Language Learning, $\quad 1-4 . \quad$ Retrieved from https://books.google.com.sa/books?hl=en\&lr=\&id=f1DwCgAAQBAJ\&oi=fnd\&pg=PA98\&dq=A+Tellecoll aborative + Approach + to + Written + Corrective + Feedback + Nahid\&ots=0Z4m7WU6YR\&sig=pedWu9ppSjSd zK7E-9biOeH7AKQ\&redir_esc $=\mathrm{y} \# \mathrm{v}=$ onepage \&q=A Tellecollaborative Approach to Writte

\section{Copyrights}

Copyright for this article is retained by the author(s), with first publication rights granted to the journal.

This is an open-access article distributed under the terms and conditions of the Creative Commons Attribution license (http://creativecommons.org/licenses/by/4.0/). 